\title{
Pulgarcito y el lobo feroz
}

Los que lloraron borrachos por el himno nacional bajo el ciclón del Pacífico o las nieves del norte.

R. Dalton

G. Amaud afirmó en el prólogo de la película "El salario del miedo": "Guatemala no existe. Lo sé porque viví allín". Es posible que se trate de una provocación exagerada pero, ¿cómo podemos estar seguros de la existencia de El Salvador? ¿Son suficientes los acordes del himno nacional y los colores blanquiazul para asegurar nuestra identidad como nación?

Parece una pregunta innecesaria. En pocos lugares del mundo se cultiva tanto el imaginario colectivo nacionalista como en esta franja de territorio a orillas del Pacífico. Las celebraciones por la independencia pronto se encargarán de recordárnoslo. Todos de pie y la mano a la altura del corazón en señal de respeto. Durante un mes entero, la enseña patria preside la portada de los diarios y el día $d$, las cachiporristas de los desfiles se convertirán en sacerdotisas de una liturgia de erotismo blando y nacionalismo duro. Por no hablar del "Día de la Raza" (de qué raza), o de los colores omnipresentes de escuelas, estadios y puestos de salud.

El sentimiento de salvadoreñidad sirve como golosina al espíritu de los buenos patriotas. Pero eso por sí solo no asegura la existencia como nación. Tampoco la Constitución, la emisión de moneda ni los horribles bustos de los próceres instalados en la Autopista Sur. Ni siquiera la existencia de un ejército que nos defienda ( ¿de quién?) es garantía en sí misma de que existamos.

Para estar seguros es necesario que revisemos de qué está compuesta nuestra identidad. ¿Qué es lo que somos? ¿En qué nos parecemos a nuestros vecinos y qué es lo que nos diferencia de ellos? ¿De qué está hecho, en suma, el ser salvadoreño? 


\section{La Sigüanaba versus Micky Mouse}

Todos los pueblos del mundo tienen, sino la obligación, al menos el derecho de hacerse esta misma pregunta. Muchos de ellos encuentran la respuesta en la historia o en rasgos culturales únicos (lengua, tradiciones...) que a lo largo de los siglos han conformado su peculiar idiosincracia. ¿Y nosotros?

Revisemos nuestra historia. Para bien, o mucho más probablemente para mal, la historia de las gentes que habitaron el territorio que hoy llamamos El Salvador está marcada por la conquista. La flecha que atravesó la pierna de Pedro de Alvarado representa simbólicamente un antes y un después en la historia.

Sin duda alguna, el Señorío de Cuscatlán es el mejor referente al que podemos acudir en busca de nuestras raíces. Que actualmente sus principales ruinas se encuentren sepultadas bajo el edificio de la embajada de los Estados Unidos (la Embajada con mayúsculas, como se suele escribir) es sólo una ironía del destino que se presta a interpretaciones malintencionadas y metáforas fáciles.

Que sus habitantes llegaran empujados de otras tierras huyendo de la ferocidad de los aztecas, que el náhuatl se haya hablado en todo Centroamérica o que los lencas habitaran también gran parte de lo que hoy es Honduras son, sin embargo, elementos que hablan más de lo que nos asemeja a nuestros vecinos que de lo que nos diferencia.

Lamentablemente la herencia de los pueblos anteriores al encontronazo con los españoles se reduce a vestigios arqueológicos. La conquista hizo desaparecer, en gran parte, la identidad indígena. $Y$ en nuestro país, sucesos históricos posteriores acabaron de reducirla hasta convertirla en poco más que el jaguar emblemático del Banco Cuscatlán.

Pero si en la historia presalvadoreña es difícil encontrar bases que ayuden a cimentar el entusiasmo nacionalista del presente, lo es aún más en el período colonial.

El imperio español uniformó -y unificó- el universo simbólico de toda América Latina. Un aluvión de santos pasaron a nombrar las poblaciones (San Salvador, San Miguel, Santa Ana... - y en nuestro caso quién sabe por qué extraña razón también sus diminutivos: San Miguelito, Santa Anita...- en definitiva, la cruz y la espada) y redujeron nuestro conocimiento sobre el náhuatl a lo que hoy podemos aprender de un puñado de toponimias. Y como por añadidura, esos santos nos legaron para siempre su peculiar manera de concebir el mundo. Aún hoy, una manifestación tan característica de nuestro folklore como son los historiantes de Nahuizalco y San Pedro Nonualco, no hace sino rememorar unos pleitos entre moros y cristianos que sucedieron a casi nueve mil kilómetros de distancia, por no referirnos al baile de los negritos, e investigar a qué negritos es a los que se refiere. De todos modos, esos detalles ya no parecen tener más interés que el antropológico. 
A los cipotes de hoy poco les importan negritos e historiantes. La tradición que realmente les pone en contacto con el fascinante mundo de lo mágico son las calabazas y las brujas - tan poco salvadoreñas-, que inundan las vitrinas de los almacenes durante la noche del halloween.

Sin duda es posible argumentar con éxito que salvadoreños y guatemaltecos no tienen idéntica cultura, pero es obvio que el sustrato español que comparten hace que la distancia entre un indigena y un ladino chapín sea mucho mayor que entre éste y su vecino guanaco.

Claro que nada es eterno y el imperio español mucho menos. Llegó Napoleón y mandó parar. En pocos años se hizo patente la inviabilidad histórica de mantener los sueños imperiales (aún no estaba de moda llamarlos imperialistas. Eso sería después). $Y$ vino la independencia.

Desde entonces la historia, con todos sus intentos frustrados de unidad centroamericana, al menos deparó a los habitantes de este pueblo una percha simbólica en la que colgar el sentimiento de identidad. Ya supieron lo que eran: salvadoreños, con himno y bandera. El tiempo se encargaría de añadir además una selección nacional capaz de marcar un gol en los mundiales de fútbol de España 82.

Pero las cosas no son tan sencillas. Una nación no nace a golpe de decreto criollo.

\section{Como señala Octavio Paz:}

El nuestro es un nacionalismo reciente. Nacido en el siglo XIX. A diferencia del europeo no es el resultado de una larga evolución histórica, sino de la desmembración del imperio español y una serie de accidentes históricos. Se olvida con frecuencia las ambiciones desmesuradas de los caudillos de la independencia. Ellos fueron los agentes activos del desmembramiento y no los pueblos. El desmembramiento no comenzó por abajo como es el caso del antiguo imperio ruso, sino que fue obra de los caudillos y de ciertas minorías.

Claro que Octavio Paz no se refiere exclusivamente a El Salvador, sino al conjunto de países de América Latina. Y concluye que se trata de naciones creadas después de la independencia y no antes. Pero algunas de esas naciones nacientes, como es el caso del Perú o de México, contaban en su haber con una civilización precolombina extraordinaria, que facilitaba la construcción nacional de su identidad. El resto tuvieron que conformarse, siempre siguiendo al escritor mexicano, "con una geografía política irracional, hija de su historia desventurada y del fracaso de la independencia".

$Y$ es que cuando hay eventos centroamericanos y el protocolo coloca todas las banderas juntas, como parecen iguales, uno ni identificarse puede. $Y$ eso que acá no compiten argentinos ni uruguayos. Con su aporte apreciaríamos toda la 
gama de combinaciones blanquiazules que nacieron como enseñas-naufragio del imperio colonial y del sueño de Bolívar.

Así, pues, ¿en qué momento se consumó la creación de nuestra nación? ¿o será que se trata de un proceso inconcluso que nos ha dejado a medias el proyecto de identidad?

Bien pudiera ser que al igual que la geología nos muestra una naturaleza inacabada sacudida periódicamente por temblores y por volcanes, la historia nos haya legado una nación incompleta, cuya terminación pretendemos con un exceso de banderas bicolores y golpes de pecho.

Porque El Salvador es un país con poca historia. O, mejor dicho, con muy poca atención en su historia. Quizás por eso de sus más de cuarenta universidades, hasta hace poco ninguna ofrecía esos estudios. Y quizás también por eso es posible que la exhumación en una iglesia de unos restos del siglo XIX, aparezca en la prensa como si se tratara de un hallazgo arqueológico, cuando en verdad pudiera tratarse de la tumba de cualquiera de nuestros abuelos.

Si compartimos con nuestros vecinos los orígenes, la historia, los colores nacionales, muchos de los próceres y -sobre todo- participamos de la misma situación social y el mismo éxodo migratorio forzoso hacia la tierra prometida del norte (que algo deben tener que ver el millón de salvadoreños en Estados Unidos con la presencia de los colores azul y blanco en su bandera). Si compartimos todo eso, ¿qué es lo que nos hace ser diferentes?

Se objetará que la identidad de un pueblo no proviene únicamente de su historia, que existe también un cúmulo de tradiciones, arte y religión que moldean el espíritu colectivo y le otorgan sentido de pertenencia.

El Salvador ha tenido, como todos los pueblos, sus intelectuales y escritores. Gavidia, Masferrer o Salarrué lo atestiguan. Y aunque ninguno de ellos -las cosas como son - haya alcanzado una dimensión universal con su pensamiento o sus letras, sí constituyen el germen sobre el cual levantar un acervo cultural propio.

El arte también aporta su granito de arena en esta tarea identificatoria. El Salvador es reconocido por los colores vivos y la estética naif de la artesanía de La Palma. Sin embargo, los dibujos planos y multicolores de pájaros, ranchitos y animales que nos identifican no son una herencia de antiguas tradiciones populares, sino un bonito invento de un grupo de artistas lidereados por Fernando Llort. Este detalle no quita ningún mérito estético, pero un arte con menos de treinta años de edad es un poco joven para aspirar a convertirse en la expresión artística representativa de un pueblo.

En cuanto a la religión, este terreno tampoco nos sirve de mucha ayuda. El profundo sentido religioso del salvadoreño tiene su santuario más venerado en 
Esquipulas, fuera de nuestras fronteras. Y la profusión de cultos evangélicos que tanto éxito están teniendo en nuestro país no aportan mucho acento local. Si uno les presta atención, más bien se puede reconocer en ellos el inglés de Estados Unidos.

Descartada también la flor del izote, que a pesar de su condición de símbolo patrio tiene su verdadero origen en tierras mexicanas, apenas nos queda la pupusa como aportación propia al desarrollo de la gastronomía mundial.

Incluso dentro de la cultura de izquierdas no fue sencillo encontrar elementos identificatorios propios. El indio Aquino y Feliciano Ama antecedieron a un Farabundo Martí, alrededor de quien se quiso recomponer un caudillaje mítico al estilo de Sandino. Pero Farabundo no fue Sandino. No tiene la misma dimensión histórica. Fue necesario rescatar a duras penas esa frase de "cuando la historia no se puede escribir con la pluma hay que hacerlo con el fusil" para poder incluir su inicial en las siglas del movimiento guerrillero unificado. Sin duda alguna, la figura de César Augusto Sandino sobrevivirá a los avatares políticos del FSLN, mientras que la de Farabundo es más que dudoso que perviva.

¿Así, pues, qué es lo que identifica a los salvadoreños en el resto del mundo, más allá de la ferocidad con la que se han matado los unos a los otros durante más de una década y de que una de sus hijas testificara en el juicio contra $O$. J. Simpson?

\section{...Y sin embargo funciona}

No se trata de cuestionar las diferentes piezas que apuntalan el rompecabezas del imaginario nacional, sino tan sólo de plantear que puede resultar útil su revisión. Lo mismo encontramos que nos quedan huecos vacíos, o que la ilustración resultante difiere un poco del modelo que diariamente nos enseñan.

Porque lo que es indudable es que la idea de nación produce un sentimiento que moviliza. Y es muy probable que la "fibra sensible" a la que llegan los himnos y banderas, sea la misma que eriza la piel durante las marchas populares o los cultos religiosos. Freud ya se ocupó de ella en Psicología de las masas.

La dificultad consiste en que a falta de una identidad terminada como nación, ese sentimiento de pertenencia al grupo corre el riesgo de ser fácilmente dirigido. Se delega en especialistas, ya se trate de políticos o intelectuales (aquellos que supuestamente están en capacidad de pensar más y mejor), la elección de la cuestión que debe provocar y el momento en que debe exteriorizarse el ímpetu nacionalista.

Porque, tanto en 1821 como hoy, la delimitación de la nación -y, por ende, del nacionalismo- se presenta en función de los intereses de aquellos sectores hegemónicos que son lo suficientemente poderosos como para poder establecerla 
gama de combinaciones blanquiazules que nacieron como enseñas-naufragio del imperio colonial y del sueño de Bolívar.

Así, pues, ¿en qué momento se consumó la creación de nuestra nación? ¿o será que se trata de un proceso inconcluso que nos ha dejado a medias el proyecto de identidad?

Bien pudiera ser que al igual que la geología nos muestra una naturaleza inacabada sacudida periódicamente por temblores y por volcanes, la historia nos haya legado una nación incompleta, cuya terminación pretendemos con un exceso de banderas bicolores y golpes de pecho.

Porque El Salvador es un país con poca historia. O, mejor dicho, con muy poca atención en su historia. Quizás por eso de sus más de cuarenta universidades, hasta hace poco ninguna ofrecía esos estudios. Y quizás también por eso es posible que la exhumación en una iglesia de unos restos del siglo XIX, aparezca en la prensa como si se tratara de un hallazgo arqueológico, cuando en verdad pudiera tratarse de la tumba de cualquiera de nuestros abuelos.

Si compartimos con nuestros vecinos los orígenes, la historia, los colores nacionales, muchos de los próceres y - sobre todo- participamos de la misma situación social y el mismo éxodo migratorio forzoso hacia la tierra prometida del norte (que algo deben tener que ver el millón de salvadoreños en Estados Unidos con la presencia de los colores azul y blanco en su bandera). Si compartimos todo eso, ¿qué es lo que nos hace ser diferentes?

Se objetará que la identidad de un pueblo no proviene únicamente de su historia, que existe también un cúmulo de tradiciones, arte y religión que moldean el espíritu colectivo y le otorgan sentido de pertenencia.

El Salvador ha tenido, como todos los pueblos, sus intelectuales y escritores. Gavidia, Masferrer o Salarné lo atestiguan. Y aunque ninguno de ellos -las cosas como son- haya alcanzado una dimensión universal con su pensamiento o sus letras, sí constituyen el germen sobre el cual levantar un acervo cultural propio.

El arte también aporta su granito de arena en esta tarea identificatoria. El Salvador es reconocido por los colores vivos y la estética naif de la artesanía de La Palma. Sin embargo, los dibujos planos y multicolores de pájaros, ranchitos y animales que nos identifican no son una herencia de antiguas tradiciones populares, sino un bonito invento de un grupo de artistas lidereados por Fernando Llort. Este detalle no quita ningún mérito estético, pero un arte con menos de treinta años de edad es un poco joven para aspirar a convertirse en la expresión artística representativa de un pueblo.

En cuanto a la religión, este terreno tampoco nos sirve de mucha ayuda. El profundo sentido religioso del salvadoreño tiene su santuario más venerado en 
Esquipulas, fuera de nuestras fronteras. Y la profusión de cultos evangélicos que tanto éxito están teniendo en nuestro país no aportan mucho acento local. Si uno les presta atención, más bien se puede reconocer en ellos el inglés de Estados Unidos.

Descartada también la flor del izote, que a pesar de su condición de símbolo patrio tiene su verdadero origen en tierras mexicanas, apenas nos queda la pupusa como aportación propia al desarrollo de la gastronomía mundial.

Incluso dentro de la cultura de izquierdas no fue sencillo encontrar elementos identificatorios propios. El indio Aquino y Feliciano Ama antecedieron a un Farabundo Martí, alrededor de quien se quiso recomponer un caudillaje mítico al estilo de Sandino. Pero Farabundo no fue Sandino. No tiene la misma dimensión histórica. Fue necesario rescatar a duras penas esa frase de "cuando la historia no se puede escribir con la pluma hay que hacerlo con el fusil" para poder incluir su inicial en las siglas del movimiento guerrillero unificado. Sin duda alguna, la figura de César Augusto Sandino sobrevivirá a los avatares políticos del FSLN, mientras que la de Farabundo es más que dudoso que perviva.

¿Así, pues, qué es lo que identifica a los salvadoreños en el resto del mundo, más allá de la ferocidad con la que se han matado los unos a los otros durante más de una década y de que una de sus hijas testificara en el juicio contra $O$. J. Simpson?

\section{...Y sin embargo funciona}

No se trata de cuestionar las diferentes piezas que apuntalan el rompecabezas del imaginario nacional, sino tan sólo de plantear que puede resultar útil su revisión. Lo mismo encontramos que nos quedan huecos vacíos, o que la ilustración resultante difiere un poco del modelo que diariamente nos enseñan.

Porque lo que es indudable es que la idea de nación produce un sentimiento que moviliza. Y es muy probable que la "fibra sensible" a la que llegan los himnos y banderas, sea la misma que eriza la piel durante las marchas populares o los cultos religiosos. Freud ya se ocupó de ella en Psicología de las masas.

La dificultad consiste en que a falta de una identidad terminada como nación, ese sentimiento de pertenencia al grupo corre el riesgo de ser fácilmente dirigido. Se delega en especialistas, ya se trate de políticos o intelectuales (aquellos que supuestamente están en capacidad de pensar más y mejor), la elección de la cuestión que debe provocar y el momento en que debe exteriorizarse el ímpetu nacionalista.

Porque, tanto en 1821 como hoy, la delimitación de la nación $-\mathrm{y}$, por ende, del nacionalismo- se presenta en función de los intereses de aquellos sectores hegemónicos que son lo suficientemente poderosos como para poder establecerla 
a su medida. Y este análisis no es necesaria ni exclusivamente marxista, sino que se trata de una realidad empírica.

Vázquez Montalbán ha descrito cómo - ahora y siempre - los políticos pueden ver mejorada considerablemente su imagen pública a través de un hábil manejo del sentimiento de grupo. El guerrerismo inflama los espíritus y, lo que es más importante, hace ganar elecciones. Y no se trata de caudillismos ancestrales. Margaret Thatcher o George Bush reconvirtieron los muertos de las Malvinas y el Golfo Pérsico en carisma personal. Y es asombrosamente infantil el recurso de Bill Clinton a bombardear oriente en los momentos más agudos de la crisis Lewinski.

Esto no es nuevo ni ajeno. En nuestra historia reciente, el FMLN comprendió muy pronto que resultaría rentable incorporar el himno y las enseñas patrias a su repertorio de liturgias revolucionarias. No en vano cuando fue preciso reconvertirse en una estructura lo más similar posible a un ejército regular de cara al conteo de fuerzas por parte de la Onusal, eligieron el nombre de Ejército Nacional (ni popular ni revolucionario) para la Democracia.

Cuando el extinto (o la extinta, que al final fue pura ambigüedad de género) ERP culminó su proceso de desidentificación como parte de la izquierda. En un ejercicio admirable de prestidigitación política salió de la chistera reconvertido en PD y rodeado de himno, videoclip nacionalista y cientos de globos ¿cómo no? Azules y blancos. Ninguna referencia al rojo - color maldito-.

En el otro extremo del espectro político, la utilización y el intento de monopolización del sentimiento nacionalista por parte de ARENA, es demasiado obvia para que merezca la pena detenerse en ella.

El recurso a excitar en algún tumor de la memoria colectiva la reconstrucción de enemigos fantasmales del pasado para que fortalezcan la propia identidad es sencillo y eficaz. Pero peligroso. Aunque la realidad histórica demuestre que nunca han existido, espolea el imaginario y establece justificaciones para luchas futuras.

Puede ser clarificador hacer una relectura de los himnos centroamericanos. Como muestra un botón.

Para los guatemaltecos:

Si mañana tu suelo sagrado lo amenaza invasión extranjera libre al viento tu hermosa bandera a vencer o a morir llamará.

En Honduras, sin embargo: Defendiendo tu santa bandera y en sus pliegues gloriosos cubiertos serán muchos, Honduras, tus muertos pero todos caerán con honor. 
Por señalar únicamente los que tenemos más cerca. Como se ve, se parecen como dos gotas de agua. En este contexto nuestra aportación "jurando la vida animosos sin descanso a su bien consagrar" no es más que una reiteración de la misma retórica. Llueve sobre mojado.

Sin embargo, si uno recuerda toda la parafernalia nacionalista que acompañó a ambos bandos en las cien horas de la guerra del fútbol, parece necesario un minuto de silencio. Por los sufrimientos provocados y por la oportunidad de reflexionar.

Si aceptamos la afirmación de Braudillard de que el posmodernismo ha hecho desaparecer el espacio público y lo ha sustituido por espacio publicitario, la consecuencia lógica es que ese espacio publicitario se presta a la demagogia. Independientemente de los fallos del tribunal internacional de La Haya y de que a los pobladores de los bolsones les concedan o no la doble nacionalidad.

Alguien con un fino sentido del humor afirmó "cada vez que escucho la palabra cultura, echo mano a la cartera", en una atinada burla de la difícil convivencia entre el arte y el mercado. Pero bien se podría aplicar la misma broma a la palabra nación. "Cada vez que la escucho, me pregunto cuáles son los intereses que están en juego". Ya se trate de juego económico, político o exclusivamente electoral.

Y es que la mención a pasadas guerras o las referencias trágicas al exterior (Chechenia, la antigua Yugoslavia....) son sólo casos extremos. En un debate sobre las medidas económicas que pretendía aprobar el gabinete, se escuchó como argumento descalificatorio que algunas de dichas medidas habían sido propuestas por organismos internacionales y no por salvadoreños. Como si la lógica de la economía tuviera algo que ver con los pasaportes y las cédulas de bautismo. Si es bueno, es bueno; y si es malo no mejora porque su promotor sea originario de Ahuachapán.

\section{Ni príncipes ni sapos}

Hace ya años que el propio concepto de nación marcha a la deriva, a punto del naufragio y sin ninguna tabla a la que poder agarrarse.

No olvidemos que el Estado-Nación no es más que una construcción histórica nacida en los ardores de la revolución francesa. Hoy parece haber dado de sí todo lo posible y agoniza sin que sepamos a ciencia cierta las características del nuevo modelo social llamado a sustituirlo.

Una cosa sí parece evidente, y es que el mundo entero se estremece entre las sacudidas de universalismos y localismos (aunque el diminuto tamaño de El Salvador lo mantenga alejado de estos últimos). 
Las cosas cambian de prisa. La nación quedó demasiado grande para gestionar unos intereses y demasiado chiquita para otros. Hoy en día, los bancos de datos de las empresas multinacionales a menudo son más poderosos que los de los estados. Y triunfan en su empeño de llenar el mundo de combos de pollo y papas con ketchup.

No es sólo la economía. El parlamento centroamericano, como símbolo de la integración regional, se debate entre la aspiración histórica y la inutilidad práctica. Por mucho que añadamos la palabra Centroamérica a los remites de las tarjetas postales y a las placas de los carros. Que no por eso la mayoría dejan de ser japoneses.

No parece posible defender un nacionalismo que no esté sostenido en el concepto de nación. Nacionalismo, que por cierto nunca logró hacer buenas migas con la izquierda. Esta siempre tuvo una vocación universalista por más que Yaseer Arafat, el Congreso Nacional Africano o los vascos abertxales tanto se hayan esforzado en malabarismos dialécticos en busca de la cuadratura nacional del círculo socialista. La sola unión de las palabras nacional y socialista evoca otros fracasos históricos de peores consecuencias.

Claro que es preciso defender el derecho a la diferencia. Pero habrá que reivindicarlo siendo conscientes de los peligros que entraña buscar la identidad a costa del Otro. Proclamarse diferente puede ser al paso previo a declararse mejor. Y ahí comienzan los problemas. Además, no podemos olvidar que preservar pura nuestra propia cultura implica enfrentarse a una parte de nosotros mismos. $Y$ en eso nos abocamos a un costoso fracaso.

Reivindiquemos mejor el mestizaje. Al fin y al cabo, nuestra sangre y nuestra cultura son de origen tan mestizo que no nos caería bien ponernos puristas en esto de la identidad nacional. Total, los frijoles no se llevan tan mal con la cocacola ( $\mathrm{y}$ aunque asi fuera, no tendría remedio).

Tal como están las cosas parece recomendable emprender la tarea de repensar la Nación (y sus atributos) y aprender a descodificar todos los mensajes y, muy particularmente, las exaltaciones nacionalistas.

Porque siempre es útil decir las cosas en nombre de alguien (y cuanto más sagrado mejor): ahorra tiempo, quebraderos de cabeza y da solidez a nuestras propuestas. Y si lo escribimos en mayúscula igual funciona que sea en nombre de Dios, de la Patria, de la Vanguardia Proletaria o del Pueblo Salvadoreño.

$Y$ es que con esto de las categorías hay que tener cuidado. Por ejemplo, esta de "pueblo" es bien difícil. Y si la deslizamos de su sentido antropológico al político, las más de las veces se nos cae y se hace añicos contra el suelo de la demagogia. Porque, ¿quién es ese sujeto colectivo que se llama pueblo?, ¿los ciudadanos que no llegan al salario mínimo?, ¿los lectores de periódicos?, ¿los campesinos?, ¿los votantes de los partidos de izquierda? ... 
Así, pues, nadie duda que sea justo - y necesario - un esfuerzo que ayude a identificar los elementos culturales más característicos de esta tierra. Pero tengamos cuidado cada vez que nos pongamos roncos de entonar el himno nacional, no vaya a servir nunca como legitimación providencialista. No olvidemos que, en su momento, algo en apariencia tan bonito como el grito de primero $\mathrm{El}$ Salvador, segundo El Salvador y tercero El Salvador, pudo servir de coartada para la desaparición física de miles de salvadoreños.

No vaya a ser que tras la inocente imagen de Pulgarcito que en su día nos dedicó Gabriela Mistral, vuelva a aparecer de nuevo la sombra del Lobo Feroz.

\section{Nota}

1. Antropólogo social. 